\title{
A COMPARISON OF POST-OPERATIVE ANALGESIA WITH INTRAOPERATIVE PECTORAL NERVE BLOCK VERSUS CONVENTIONAL TECHNIQUE IN PATIENTS UNDERGOING MODIFIED RADICAL MASTECTOMY: A PROSPECTIVE, RANDOMIZED, AND DOUBLE-BLINDED STUDY
}

\author{
ANKITA GAUTAM, DAISY KARAN, SWARNA BANERJEE, PRERNA BISWAL*, NUPUR MODA
}

Department of Anesthesiology, IMS and SUM Hospital, Bhubaneswar, Odisha, India. Email: prerna.biswal@gmail.com

Received: 11 September 2021, Revised and Accepted: 25 October 2021

ABSTRACT

Objective: We administered intraoperative pectoral nerve block after tissue resection was over and assessed its analgesic efficacy with conventional post-operative intravenous opioids in patients undergoing modified radical mastectomy.

Methods: Sixty patients undergoing modified radical mastectomy surgery were enrolled in this prospective, randomized, and doubleblinded study. After general anesthesia and surgical resection in both groups, Group P received pectoralis (PECS) block under vision with ropivacaine at two points: $20 \mathrm{ml}$ in the fascia over serratus anterior and $10 \mathrm{ml}$ in the fascia between pectoral major and minor at the level of the third rib and Group T received tramadol $(75 \mathrm{mg}$ ) in thrice daily frequency and $2 \%$ lignocaine infiltration at suture site. Primary objectives were to assess visual analog scale (VAS) scores over $24 \mathrm{~h}$, time to first request for rescue analgesia (ketorolac) and total dose of analgesics needed, and secondary outcome was adverse effects and patient satisfaction score. "Mann-Whitney U test" and "Chi-square/Fischer exact test" were used for quantitative and categorical variables, respectively.

Results: The mean time to the first rescue analgesia was $1175 \pm 120.21$ and $1175 \pm 77.35$ min and total analgesia requirement was equal ( $30.00 \pm 0.00 \mathrm{mg}$ ) in Group P and Group T, respectively. The mean VAS score over $24 \mathrm{~h}$ was comparable in both the groups. PECS block group had significantly less adverse effects and better satisfaction score.

Conclusion: PECS block has similar analgesic efficacy as opioids but with better ability to mobilize the respective arm, better patient satisfaction score, and lesser adverse effects.

Keywords: Breast cancer, Modified radical mastectomy, Pectoral nerve block, Post-operative pain, Ropivacaine.

(c) 2021 The Authors. Published by Innovare Academic Sciences Pvt Ltd. This is an open access article under the CC BY license (http://creativecommons.org/ licenses/by/4.0/) DOI: http://dx.doi.org/10.22159/ajpcr.2021v14i12.43107. Journal homepage: https://innovareacademics.in/journals/index.php/ajpcr

\section{INTRODUCTION}

Almost $43 \%$ patients with breast cancer require mastectomy. Analgesic protocols used to treat post-mastectomy pain vary significantly. Perioperative analgesia utilizes significant quantities of opioids in these categories of patients. This leads to an increase in opioid related side effects. Regional anesthesia includes various nerve blocks such as paravertebral block, thoracic epidural, and pectoralis (PECS) block. Besides these infiltrations with local anesthesia performed by surgeon helps. Recent data have shown liposomal bupivacaine given through infiltration to be an effective adjunct for post-operative pain control in breast augmentation and reduction [1]. Ultrasound-guided pectoral nerves blocks (Type I and II) has better analgesic quality in post-operative period with lesser adverse effects such as postoperative nausea and vomiting (PONV) when compared to opioids [2]. However, it requires trained personnel and an ultrasound machine [3]. There are studies reported in which PECS block when administered before general anesthesia (GA), led to the spread of local anesthetics (LAs) along the fascial planes and limited the use of electrocautery during surgery. In the presence of fluid, electrocautery fails to work at a current strength of $50 \mathrm{~mA}$. It also leads to distortion of surgical plane and hemorrhagic spots due to multiple injections decreases the clarity during surgical dissection [4]. Intraoperative PECS block has been performed successfully by Thomas et al., which could reduce post-operative analgesic requirement significantly avoiding the above problems [5]. We evaluated and compared the efficacy of intraoperative PECS block with the standard practice of LA infiltration and intravenous tramadol. Intravenous tramadol along with local infiltration has been used in many surgeries as a multimodal analgesic regimen. When combined with nonsteroidal anti-inflammatory drugs they provide adequate post-operative analgesia. So considering the above fact in to account our objectives was to report the true clinical effectiveness of both the analgesic practices by balancing the invasiveness of the analgesic interventions, as well as their adverse effects.

\section{METHODS}

This study was designed as a prospective, randomized, double-blinded study, and conducted from the period of August 2018 till August 2020 (24 months). After obtaining clearance from Institutional Ethical Committee, female patients of age 20-70 years belonging to American Society of Anesthesiology (ASA) physical status 1 or 2 undergoing modified radical mastectomy (MRM) with axillary dissection were selected for the study. Patients with any history of allergy to LA drugs, with the previous history of bleeding tendencies or on anticoagulant medication, with body mass index more than $35 \mathrm{~kg} / \mathrm{m}^{2}$ and patients being treated for chronic pain disorders were excluded from the study. Valid informed written consent was taken from each patient. The sample size was calculated based on a pilot study. Assuming a difference in rescue analgesic consumption of $30 \%$ and power of study as $80 \%$ with confidence interval of $95 \%$, the sample size was calculated as 27 . To minimize any effect on data, we have taken 32 samples in each group, assuming approximately $10 \%$ as dropout rate. Randomization of patients was done through computer-generated numbers and the patients were divided in two groups: Group "T" received intravenous tramadol before wound closure and bupivacaine infiltration at suture site. Group "P" received PECS II block before skin suture. It is shown in consort flow diagram. All patients were taught how to define pain using the visual analog score (VAS) $0-10 ; 0=$ no pain, $1-3=$ mild pain, 
$4-6=$ moderate pain, and $7-10=$ severe pain during the pre-operative visit.

After complete pre-anesthetic check-up, screening for eligibility and overnight fasting, patients were prepared with premedications, tablet alprazolam $(0.5 \mathrm{mg})$ night before surgery and tablet ranitidine (150 mg) and intravenous midazolam $0.02 \mathrm{mg} / \mathrm{kg}$ on the morning of surgery. The standard ASA monitoring was instituted for all the patients. After inj. fentanyl ( $2 \mathrm{mcg} / \mathrm{kg}$ ), induction of general anesthesia was done with injection propofol $(2-3 \mathrm{mg} / \mathrm{kg})$ and injection vecuronium $(0.8-1 \mathrm{mg} / \mathrm{kg})$. All patients were intubated through a cuffed endotracheal tube of appropriate size, and maintenance of anesthesia was done with isoflurane to achieve 0.8-1.0 minimum alveolar concentration and intermittent doses of injection vecuronium. For any intraoperative increase in heart rate and systolic blood pressure of more than $20 \%$ from the baseline value, intravenous fentanyl $0.25 \mu \mathrm{g} / \mathrm{kg}$ was administered.

The code allocation corresponding to the PECS group and the Tramadol and local infiltration group were given to the consultant anesthesiologists in non-transparent envelopes which they opened in the operation theatre toward the completion of the surgery. Patients were given either PECS block under vision by the surgeon or intravenous tramadol with $0.5 \%$ bupivacaine infiltration at suture site, depending on the group they were allocated before the surgery.

In Group P, after the wash of the wound and insertion of the drain, PECS (II) block was performed after identifying the medial and lateral pectoral nerves. First $10 \mathrm{ml}$ injection of a solution containing $0.2 \%$ ropivacaine and $8 \mathrm{mg}$ dexamethasone was given making a bulge around the above two nerves (Fig. 1a). In the second injection, $20 \mathrm{ml}$ of drug solution was given at a parallel course of the long thoracic nerve in between the pectoral minor and serratus anterior planes (Fig. 1b). After completion of the PECS block procedure, the wound was closed and extubation was done.

In Group T, patients received intravenous tramadol $1.5 \mathrm{mg} / \mathrm{kg}$ in $100 \mathrm{ml}$ NS solution before closure of the wound and then every $8^{\text {th }}$ hourly in the surgical ward along with $20 \mathrm{ml}$ of $0.5 \%$ bupivacaine to which $1 \mathrm{ml}$ adrenaline was added ( 1 in 10000 dilutions) infiltrated at the suture site before extubation. Prophylactic ondansetron $0.1 \mathrm{mg} / \mathrm{kg}$ was given as antiemetic. After reversal of neuromuscular blockade and recovery from anesthesia patients were shifted to recovery room. The participants (patients) and principal investigators were blinded to group allocations and the post-operative orders. The principal investigator recorded the VAS score at $1^{\text {st }} \mathrm{h}$ in the recovery room. In the post-operative period both groups of patients received injection ketorolac $30 \mathrm{mg} \mathrm{I} / \mathrm{V}$ stat as the rescue analgesic, if the VAS score was more than 4 . The observation, recording, tabulation, and statistical evaluation of the data were done by an independent analyst.

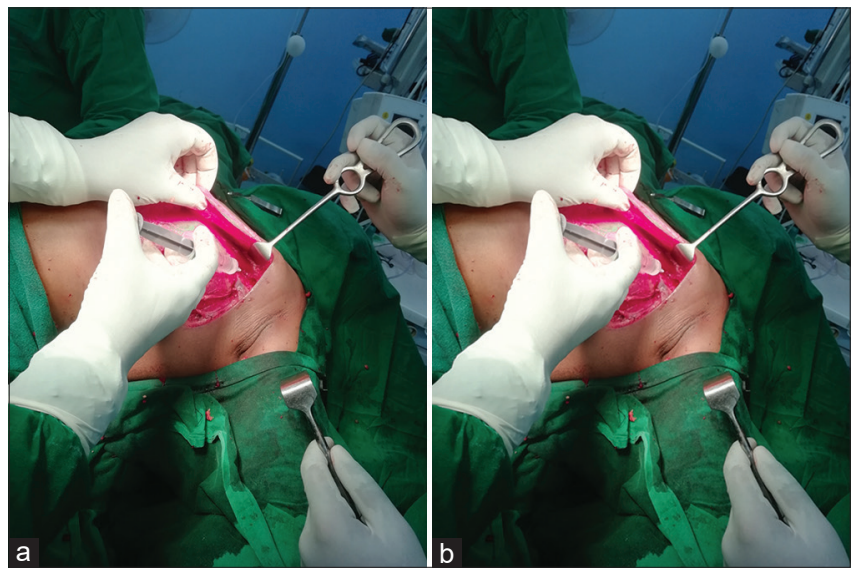

Fig. 1: Injection area. (a) Injection around medial and lateral pectoral nerve, (b) injection parallel to the long thoracic nerve
The primary objectives were to compare:

1. Post-operative pain scores at rest (VAS score at rest) and during $60^{\circ}-90^{\circ}$ abduction of the ipsilateral arm (VAS score on abduction) at $1,6,12,18$, and 24 h postoperatively, between the two groups

2. Duration of analgesia time to first request of analgesia (intravenous ketorolac) from the end of the surgery

3. Total analgesia requirement in the postoperative period (intravenous ketorolac consumption) within the first $24 \mathrm{~h}$ in both the groups to maintain VAS $<4$.

The secondary objectives were to assess: Adverse effects such as PONV defined as episodes of retching or nausea or visible vomitus within $24 \mathrm{~h}$ of surgery, urine retention, ileus, pruritus, and LA toxicity in the postoperative period between the two groups and the satisfaction score at the end of $24 \mathrm{~h}$ on a Likert scale of 1-5, (1 - most dissatisfied and 5 - very satisfied).

The data for the study were analyzed with software "Statistical Package for the Social Sciences, version 25, SPSS Inc., Chicago, Illinois, USA." The quantitative variables were expressed as mean and standard deviation where categorical variables were expressed in frequency percentage. All quantitative variables were analyzed through the "Mann-Whitney U test" as they were not present in a normal distribution. However, categorical variables were analyzed by the "Chi-square/Fischer exact test." $\mathrm{p}<0.05$ was considered as statistically significant.

\section{RESULTS}

A total of 68 patients were assessed for eligibility. Among them, four patients did not give consent to get enrolled in the study. Remaining 64 patients were allocated in each group for the study. Both groups included 32 patients each. Three patients did not respond to the questionnaire. One patient was excluded from the study as immediately after the infiltration of solution leakage of infiltrate was noted from the injection site before skin closure (Fig. 1). Hence, we had thirty patients in Group $\mathrm{P}$ and thirty patients in Group $\mathrm{T}$ for the final analysis.

The two groups were comparable with respect to age, height, weight, and duration of surgery, (Table 1). The mean time to the first rescue analgesia in Group P was $19.6 \pm 2 \mathrm{~h}$ and $19.6 \pm 1.3 \mathrm{~h}$ in Group T was $(p=1.000)$ which was statistically insignificant (Table 2). Two out of 30 patients in the PECS group required rescue analgesia while four out of 30 patients in the tramadol group requested for rescue analgesia, on comparison this was found to be statistically insignificant (Table 3). The total analgesic requirement in both the groups was the same as $30.00 \pm 0.00 \mathrm{mg}$ of ketorolac and was statistically insignificant $(\mathrm{p}=0.368)$ as shown in Fig. 2. The VAS scores in both the groups at rest as well as during abduction of operated side arm were comparable and statistically insignificant, as shown in Tables 4 and 5. There was no case reported of local anesthesia systemic toxicity. Three patients complained of nausea

Table 1: Demographic profile of the patients

\begin{tabular}{llll}
\hline \multirow{2}{*}{$\begin{array}{l}\text { Demographic } \\
\text { profile }\end{array}$} & $\begin{array}{l}\text { Group P } \\
\text { Mean } \pm \text { SD }\end{array}$ & Group T & \\
\cline { 3 - 4 } & & Mean \pm SD & p-value \\
\hline Age (years) & $49.20 \pm 8.46$ & $48.6 \pm 7.30$ & 0.770 \\
Height $(\mathrm{cm})$ & $158.50 \pm 7.07$ & $157.97 \pm 7.18$ & 0.773 \\
Weight $(\mathrm{kg})$ & $61.90 \pm 7.13$ & $62.13 \pm 8.20$ & 0.907 \\
\hline
\end{tabular}

Table 2: Duration of surgery and time to first request of analgesia

\begin{tabular}{llll}
\hline $\begin{array}{l}\text { Duration of surgery } \\
\text { and time to first } \\
\text { analgesia }\end{array}$ & $\begin{array}{l}\text { Group P } \\
\text { Mean } \pm \text { SD }\end{array}$ & $\begin{array}{l}\text { Group T } \\
\text { Mean } \pm \text { SD }\end{array}$ & p-value \\
\hline $\begin{array}{l}\text { Duration of surgery } \\
\text { (in min) }\end{array}$ & $118.83 \pm 12.64$ & $124.67 \pm 12.79$ & 0.081 \\
$\begin{array}{l}\text { Time to first } \\
\text { analgesia required }\end{array}$ & $1175.00 \pm 120.21$ & $1175.0 \pm 77.35$ & 1.000 \\
\hline
\end{tabular}


Table 3: Number of the patients requiring analgesia

\begin{tabular}{llll}
\hline Groups & \multicolumn{2}{l}{ Analgesia required } \\
\cline { 2 - 4 } & Yes & No & p-value \\
\hline Pectoral nerve block (\%) & $2(6.7)$ & $28(93.3)$ & 0.671 \\
Tramadol with local & $4(13.3)$ & $26(86.7)$ & \\
lignocaine infiltration (\%) & & & \\
\hline
\end{tabular}

Table 4: Pain score at rest

\begin{tabular}{llll}
\hline Time interval & $\begin{array}{l}\text { Group P } \\
\text { Mean } \pm \text { SD }\end{array}$ & $\begin{array}{l}\text { Group T } \\
\text { Mean } \pm \text { SD }\end{array}$ & p-value \\
\hline Pain at rest $1 \mathrm{~h}$ & $0.00 \pm 0.00$ & $0.00 \pm 0.00$ & \\
Pain at rest 6 h & $0.17 \pm 0.38$ & $0.20 \pm 0.41$ & 0.744 \\
Pain at rest 12 h & $0.17 \pm 0.38$ & $0.20 \pm 0.41$ & 0.744 \\
Pain at rest 18 h & $0.50 \pm 0.57$ & $0.47 \pm 0.57$ & 0.822 \\
Pain at rest 24 h & $0.60 \pm 0.72$ & $0.63 \pm 0.72$ & 0.859 \\
\hline
\end{tabular}

Table 5: Pain score at abduction of arm

\begin{tabular}{llll}
\hline Time interval & $\begin{array}{l}\text { Group P } \\
\text { Mean } \pm \text { SD }\end{array}$ & $\begin{array}{l}\text { Group T } \\
\text { Mean } \pm \text { SD }\end{array}$ & p-value \\
\hline Pain at abduction 1 h & $1.00 \pm 0.00$ & $1.00 \pm 0.00$ & \\
Pain at abduction 6 h & $1.00 \pm 0.00$ & $1.00 \pm 0.00$ & \\
Pain at abduction 12 h & $1.17 \pm 0.38$ & $1.20 \pm 0.41$ & 0.744 \\
Pain at abduction 18 h & $1.27 \pm 0.52$ & $1.47 \pm 0.63$ & 0.185 \\
Pain at abduction 24 h & $1.30 \pm 0.60$ & $1.50 \pm 0.73$ & 0.250 \\
\hline
\end{tabular}

in Group P. 24 patients complained of nausea and six patients had PONV in Group T. Hence, side effects were statistically more in Group T $(p=0.000)$. The overall patient satisfaction at $24 \mathrm{~h}$ postoperatively.

The overall patient satisfaction at 24 hours post-operatively was statistically better in pectoral nerve block group (Fig. 3).

The Consort flow diagram depicts the enrollment and randomization of patients (Fig. 4).

\section{DISCUSSION}

Recently various kinds of regional anesthesia are taking over the opioids for post-operative analgesia in patients with breast cancer surgeries and have shown significant benefits with minimum adverse effects and better satisfaction [6].

Blanco [7] has shown excellent analgesic benefits of an ultrasound-guided pectoral nerve block with LAs for patients with MRM. However, when PECS block was given in the pre-operative period, it caused the distortion of the anatomy of fascial planes due to the spread of LAs in between them, leading to dissatisfaction among surgeons [4]. Hence, in the above study PECS block was given intraoperatively under direct vision.

This randomized double-blind trial compared the conventional technique of using intravenous opioid and local infiltration at suture site with intraoperative PECS II block which was administered by the surgeons after completion of the surgery, washing of the wound, and insertion of the drain. This led to proper identification of nerves and perineural deposition of drug unlike fascial deposition in the originally described ultrasound guided PECS block. In the first injection, we localized the medial and lateral pectoral nerve and injected $10 \mathrm{ml}$ of solution making a bulge around these two nerves. Then, we asked the surgeons to inject $20 \mathrm{ml}$ of drug solution containing $0.2 \%$ ropivacaine and dexamethasone $8 \mathrm{mg}$ at a parallel course of the long thoracic nerve in between the pectoral minor and serratus anterior planes to block the sensory innervation of thoracic intercostal nerves of II-VI level and this also helped in spreading the local anesthetics toward axilla and blocked long thoracic nerve and thoracodorsal nerve [8].

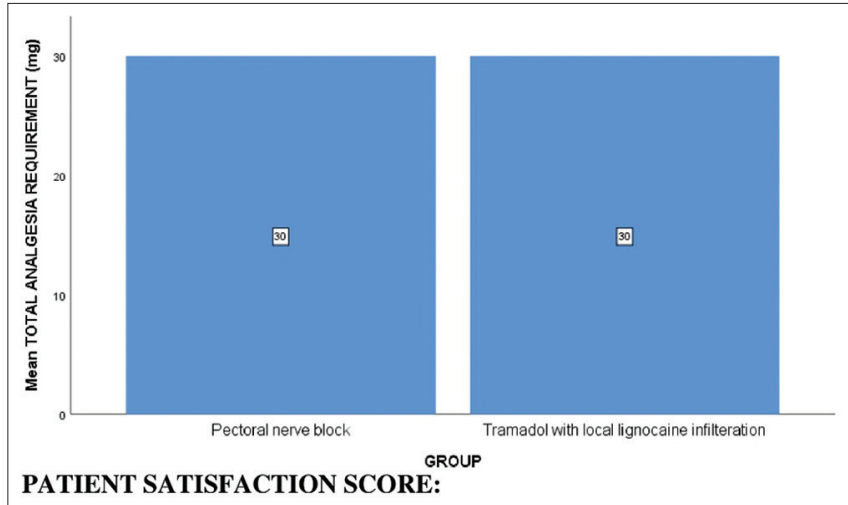

Fig. 2: Total analgesia requirement (mg)

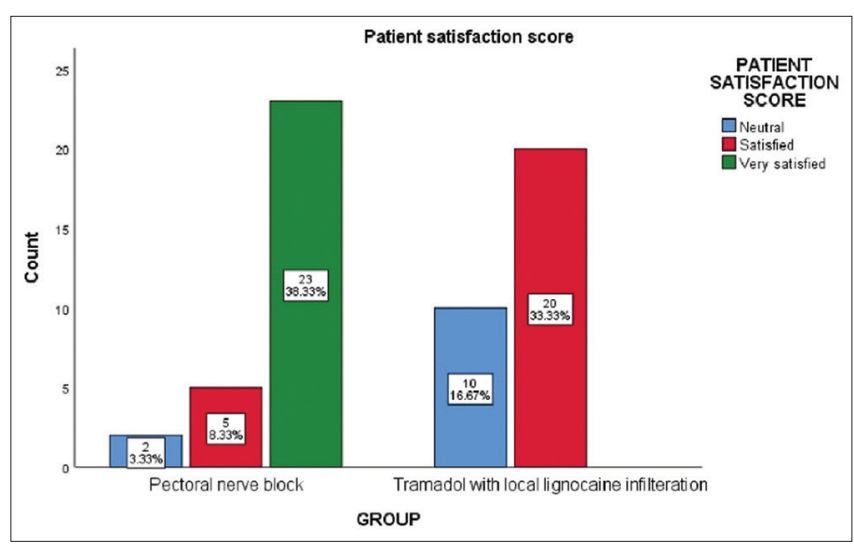

Fig. 3: Patients' satisfaction score at $24 \mathrm{~h}$

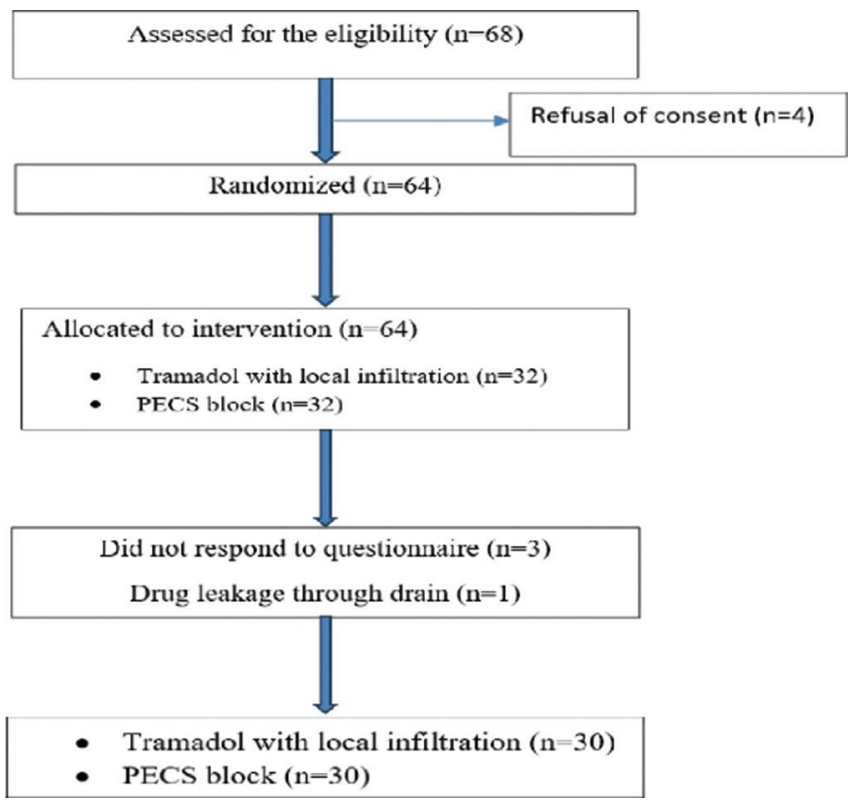

Fig. 4: Consort flow diagram

Due to anatomical reasons PECS block cannot reliably provide sufficient analgesia to the axilla (i.e., T 1 nerve distribution) [9]. Local infiltration is an old method of analgesia [10]. Thus, LA infiltration could be beneficial in these cases. This could have been the reason why the patients in Group T of our study who received intravenous opioid along with local infiltration had similar VAS scores as Group P. In our study, this technique was combined with intravenous tramadol given at thrice daily frequency. Tramadol is a centrally-acting atypical opioid analgesic 
with a dual mechanism of action. It is an opioid agonist and inhibitor of norepinephrine and serotonin re-uptake.

In a systemic review by Byager et al. wound infiltration showed less effectiveness in controlling post-operative pain beyond few hours [11]. We had hypothesized that nerve block group will fare better results as compared to the other group. However, in our study, the mean VAS score in patient receiving the PECS block was $(1.14 \pm 0.12)$ throughout $24 \mathrm{~h}$ in post-operative period which was much similar to VAS in Group $\mathrm{T}$ at all times throughout $24 \mathrm{~h}$ (Tables 4 and 5). The results in both the groups suggested equal efficacy for abolishment of post-operative pain. This suggests that multimodal techniques are equally efficacious to regional nerve blocks. Number of patients needing rescue analgesia was less in PEC group than in tramadol and local infiltration group $(6.7 \%$ vs. $13.3 \%$ ). Although total rescue analgesic requirement in both the group of patients was similar, which was $(30.00 \pm 0.00 \mathrm{mg})$ of ketorolac and hence statistically insignificant $(\mathrm{p}=0.358)$.

Although the VAS scores difference was statistically insignificant in patients with PECS block versus intravenous tramadol with LA infiltration group, clinically patients who received pectoral nerve block had improved satisfaction score measured on the Likert scale as $76.7 \%$ patients displayed "very satisfied" results compared to none in Group T, due to the better mobilization of the arm and being able to perform minimum required daily activities, and less adverse effects in comparison to opioids groups. In the tramadol group $66.7 \%$ $(\mathrm{p}=0.00)$ patients were "satisfied." The PECS group patients were more comfortable and less skeptical in moving the arm in contrary to the tramadol group patients who were more hesitant in moving the arm.

Kamiya et al. [12] suggested a significant improvement in the postoperative nausea vomiting when PECS block was compared to GA. Above results were produced due to decreased intraoperative and postoperative opioid requirements. In our study, since the PECS block was given intraoperatively, adverse effects were less in PECS group as we could avoid the use of post-operative opioids similar as above. Patients in the tramadol group had more episodes of PONV (50\% vs. 5\%), which can be attributed to the use of tramadol. There were no cases of serious adverse effects such as LA systemic toxicity in any of the groups of our study.

The block was performed in anesthetized patients hence patients' discomfort due to a breach in privacy was avoided. We also added dexamethasone with ropivacaine to prolong the effect of pectoral nerve block up to first $24 \mathrm{~h}$, when there is maximum prostaglandins release causing maximum pain. The time required to administer the block was $<3$ min because of already identified nerve structures in the intraoperative period, this quality is highly desirable in high turnover centers.

Ropivacaine $0.2 \%$ was used for pectoral nerve block which has lower motor block characteristics resulting in better patient arm mobility and hence better satisfaction score [13]. Due to direct under-vision administration of drug, we could avoid the complications such as inadvertent intravascular injections, bleeding, and pneumothorax.

The strength of our study was its double-blinding and randomized selection which minimized the role of bias. One of the limitations in our study was the subjective assessment of pain as we did not assess the sensory level of block objectively, although the assessment of the first request of rescue analgesia and total dose of rescue analgesic consumption overcomes this limitation. Since the block was given after the breast resection, the use of opioids in the intraoperative period was unavoidable. There are studies suggesting the effects of PECS block in reducing the pain intensity up to 7 days after breast surgeries [14,15], whereas local infiltration gives analgesia for a limited period Our study was limited to $24 \mathrm{~h}$ follow-up and did not compare the two methods beyond that period.

\section{CONCLUSION}

In this study, it was identified that intravenous tramadol and skin infiltration are equally efficacious to intraoperatively administered PECS block in controlling post-operative pain following MRM. However, PECS block provides better patient satisfaction score, due to better arm mobilization.

\section{AUTHORS CONTRIBUTION}

Dr. Ankita Gautam - Acquisition of data, writing manuscript, interpretation of data. Dr. Daisy Karan - Acquisition of data, concept and designing, data collection. Dr. Swarna Banerjee - Writing the manuscript, data collection. Dr. Prerna Biswal* - Interpretation of data, writing manuscript, final approval, corresponding author. Dr. Nupur Moda - Writing the manuscript, data collection

\section{CONFLICTS OF INTEREST}

None.

\section{AUTHORS FUNDING}

None.

\section{REFERENCES}

1. Tripathy S, Mandal I, Rao P, Panda A, Mishra T, Kar M. Opioid-free anesthesia for breast cancer surgery: A comparison of ultrasound guided paravertebral and pectoral nerve blocks. A randomized controlled trial. J Anaesthesiol Clin Pharmacol 2019;35:475.

2. Anjum K. Acute post mastectomy pain: A double blind randomised controlled trial: Intravenous tramadol vs bupivacaine irrigation through surgical drains. Med Sci 2020;152:164.

3. Blanco R. The "pecs block": A novel technique for providing analgesia after breast surgery. Anaesthesia 2011;66:847-8.

4. Bakshi S, Karan N, Parmar V. Pectoralis block for breast surgery: A surgical concern? Indian J Anaesth 2017;61:851

5. Thomas M, Philip FA, Mathew AP, Jagathnath Krishna KM. Intraoperative pectoral nerve block $(\mathrm{Pec})$ for breast cancer surgery: A randomized controlled trial. J Anaesthesiol Clin Pharmacol 2018;34:318-23.

6. Karmakar MK, Samy W, Li JW, Lee A, Chan WC, Chen PP, et al. Thoracic paravertebral block and its effects on chronic pain and healthrelated quality of life after modified radical mastectomy. Reg Anesth Pain Med 2014;39:289-98.

7. Blanco R. Pecs block and serratus plane blocks. how to explain fascial compartments. Ultrasound Med Biol 2017;43:S182-3.

8. Kumar A, Sinha C, Kumar A, Prasad C, Singh P, Priya D. Pectoral nerve versus erector spinae block for breast surgeries: A randomised controlled trial. Indian J Anaesth 2019;63:617.

9. Pawa A, Wrght J, Onwochei DN, Vargulescu R, Reed I, Chrisman L, et al. Combined thoracic paravertebral and pectoral nerve blocks for breast surgery under sedation. A prospestive observational case series. Anaesthesia 2018;73:438-43.

10. Albi-Feldzer A, Mouret Fourme EE, Hamouda S, Motamed C, Dubois PY, Jouanneau L, et al. A double blind randomized trial of wound and intercoastal sopace infiltration with Ropivacaine during breast cancer surgery: Effects of chronic post-opeartive pain. Anesthesiology 2013;118:318-26.

11. Byager N, Hansen MS, Matheisen O, Dahl JB. The analgesic effect of wound infiltration with local anaesthetics after breast surgery: A qualitative systematic review. Acta Anaesthesiol Scand 2014;58:402-10

12. Kamiya Y, Hasegawa M, Yoshida T, Takamatsu M, Koyama Y, et al. Impact of pectoral nerve block on postoperative pain and quality of recovery in patients undergoing breast cancer surgery: A randomised controlled trial. Eur J Anaesthesiol 2017;35:1.

13. Kaur A, Singh RB, Tripathi RK, Choubey S. Comparision between bupivacaine and ropivacaine in patients undergoing forearm surgeries under axillary brachial plexus block: A prospective randomized study. J Clin Diagn Res 2015;9:UC01-6.

14. Lee A, Lum M. Measuring anaesthetic outcomes. Anaesth Intensive Care 1996;24:685-93.

15. Jia Z, Fanglei H, Yang Y, Hangyu L, Zinan L. Pectoral nerve block in anesthesia for modified radical mastectomy. Medicine 2019;98:e15423. 